\title{
Evaluation of the Effect of Proton Pump Inhibitors on the Efficacy of Dacomitinib and Gefitinib in Patients with Advanced Non-Small Cell Lung Cancer and EGFR-Activating Mutations
}

\author{
Jerry Li $\cdot$ Dana Nickens $\cdot$ Keith Wilner $\cdot$ Weiwei Tan (D)
}

Received: April 14, 2021 / Accepted: May 22, 2021 / Published online: June 13, 2021

(C) The Author(s) 2021

\begin{abstract}
Introduction: Dacomitinib and gefitinib are irreversible epidermal growth factor receptor (EGFR) tyrosine kinase inhibitors (TKI) indicated for the first-line treatment of patients with advanced non-small cell lung cancer (NSCLC) and EGFR-activating mutations. Pharmacokinetic (PK) studies in healthy volunteers suggested that acid-reducing drugs such as proton pump inhibitors (PPI) decreased dacomitinib and gefitinib exposure by limiting the $\mathrm{pH}$-dependent absorption. This analysis retrospectively evaluates the effect of concomitant PPI use on dacomitinib exposure and on progression-free survival (PFS) and overall survival (OS) in patients treated with dacomitinib
\end{abstract}

J. Li

Pharmacometrics, Pfizer Inc, 500 Arcola Road, Collegeville, PA, USA

D. Nickens

Pharmacometrics, Pfizer Inc, 10555 Science Center Drive, San Diego, CA, USA

K. Wilner

Oncology, Pfizer Inc, 10555 Science Center Drive, San Diego, CA, USA

W. Tan $(\bowtie)$

Clinical Pharmacology, Pfizer Inc, 10555 Science Center Drive, CB10/002/2533, San Diego, CA 92121, USA

e-mail: Weiwei.tan@pfizer.com
$45 \mathrm{mg}$ QD or gefitinib $250 \mathrm{mg}$ QD in a 1:1 randomized phase 3 study (ARCHER 1050).

Methods: The analysis grouped all patients $(n=452)$ treated in each arm of the study as non-PPI users, PPI users, or extensive PPI users. PFS and OS data were presented by Kaplan-Meier plots and analyzed using Cox proportional hazards models. Dacomitinib exposure was compared using a linear mixed-effects model.

Results: Results showed that dacomitinib PFS and OS did not differ significantly when comparing PPI users $(N=59)$ to non-PPI users $(N=152)$, while extensive PPI users $(N=24)$ had shorter PFS [hazard ratio (HR): 1.94, $p=0.011]$ and OS (HR: 1.77, $p=0.027$ ) when compared to non-PPI users. For patients treated with gefitinib, PFS did not differ significantly when comparing PPI users $(N=51)$ and extensive PPI users $(N=19)$ to non-PPI users $(N=159)$; however, both PPI users (HR: 1.65, $p=0.007$ ) and extensive PPI users (HR: 1.70, $p=0.050$ ) had shorter OS when compared to non-PPI users. Further analysis by adjusting potential confounders indicated no statistically significant differences in PFS or OS between any PPI user vs. non-PPI user groups in the dacomitinib and gefitinib arms. PPI use did not appear to affect dacomitinib exposure.

Conclusion: In conclusion, PPI use in patients with NSCLC likely has minimal impact on dacomitinib or gefitinib efficacy despite 
decreased absorption of these drugs observed in PK studies.

Trial Registration: ClinicalTrials.gov identifier, NCT01774721

Keywords: Dacomitinib; EGFR inhibitor; Overall survival; Pharmacokinetics; Progression-free survival; Proton pump inhibitors

\section{Key Summary Points}

Dacomitinib is a tyrosine kinase inhibitor (TKI) approved for first-line treatment of patients with metastatic non-small cell lung cancer (NSCLC) involving epidermal growth factor receptor exon 19 deletion or exon 21 L858R substitution based on the results from the phase 3 trial ARCHER 1050.

Proton pump inhibitors (PPI) are widely used pharmacotherapies for gastroprotection in cancer patients but may limit the absorption of TKIs that require acidic environments for optimal dissolution, which has been shown in dedicated single-dose pharmacokinetic (PK) healthy volunteer studies for both dacomitinib and gefitinib.

This analysis evaluates the effect of concomitant PPI use on dacomitinib exposure and on both dacomitinib and gefitinib survival in patients treated in the ARCHER 1050 study.

With regard to PPI use, no significant differences were found for progressionfree survival or overall survival in patients treated with dacomitinib or gefitinib, and no significant differences were found for dacomitinib exposure.

This analysis shows that PPI use in patients with NSCLC likely has minimal impact on dacomitinib efficacy despite decreased absorption observed in a PK study.

\section{DIGITAL FEATURES}

This article is published with digital features, including a summary slide, to facilitate understanding of the article. To view digital features for this article go to https://doi.org/10.6084/ m9.figshare.14638194.

\section{INTRODUCTION}

Dacomitinib is a selective, adenosine triphosphate-competitive, irreversible, small-molecule inhibitor of the ErbB human epidermal growth factor receptor (HER) family of receptor tyrosine kinases, including epidermal growth factor receptor (EGFR) or HER1, HER2, HER4 and their oncogenic variants (i.e. EGFR with exon 19 deletions or exon 21 L858R mutation) [1]. When used as a first-line treatment in patients with EGFR mutation-positive non-small cell lung cancer (NSCLC), dacomitinib was found to statistically significantly improve progressionfree survival [2] and overall survival [3, 4] in comparison with gefitinib, a first-generation EGFR tyrosine kinase inhibitor, in a randomized, open-label, phase 3 trial (ARCHER 1050). On the basis of the results from ARCHER 1050, dacomitinib was approved for the first-line treatment of patients with metastatic NSCLC involving EGFR exon 19 deletion or exon 21 L858R substitution [5].

Cancer patients frequently take acid-reducing agents (ARA) to alleviate symptoms of gastroesophageal disease, thereby raising the potential for a common but underappreciated drug-drug interaction (DDI) that could decrease the exposure of anticancer medication and result in subsequent failure of therapy. Many approved orally administered, small-molecule tyrosine kinase inhibitor (TKI) drugs are weak bases that exhibit pH-dependent solubility [6]. Consequently, the oral bioavailability of these drugs may be significantly influenced when coadministered with ARAs. Proton pump inhibitors (PPIs) are ARAs that bind covalently to the $\mathrm{H}^{+} / \mathrm{K}^{+}$-ATPase pump and potently suppress gastric acid secretion for several days [7], making them ideal pharmacotherapies for 
gastroprotection in cancer patients [8]. However, the increase in gastric $\mathrm{pH}$ may limit the absorption of TKIs that require an acidic environment for optimal dissolution, which in turn can lead to decreased plasma exposure (area under the concentration curve [AUC]) [8]. This is concerning due to the clinical significance of exposure-response relationships of TKIs $[6,7]$.

ARCHER 1050 was a phase 3 study comparing the safety and efficacy of a second-generation EGFR-TKI, dacomitinib, versus gefitinib as first-line treatment for patients with advanced NSCLC with EGFR-activating mutations [5]. Both dacomitinib and gefitinib require acidic environments for maximal absorption, as demonstrated in their respective healthy volunteer studies testing the effect of gastric acidsuppressing agents on exposure $[9,10]$. Results from the healthy volunteer studies showed that co-administration of a single $45 \mathrm{mg}$ dose of dacomitinib with multiple doses of rabeprazole (a proton pump inhibitor) decreased dacomitinib $C_{\max }$ by $51 \%$ and $\mathrm{AUC}_{0-96 \mathrm{~h}}$ by $39 \%$, while co-administration of high doses of ranitidine (an H2 receptor antagonist [H2RA]) with sodium bicarbonate (to maintain the gastric $\mathrm{pH}$ above $\mathrm{pH}$ 5.0) decreased mean gefitinib AUC by $47 \%[11,12]$. Based on these findings, it is recommended that concomitant use of proton pump inhibitors (PPI) with dacomitinib or gefitinib should be avoided, and an H2RA can be taken at a staggered time of dacomitinib or gefitinib dosing $[11,12]$.

This analysis evaluates the effect of concomitant PPI use on dacomitinib exposure and on both dacomitinib and gefitinib survival in patients treated in the ARCHER 1050 study.

\section{METHODS}

\section{ARCHER 1050 Study Design}

ARCHER 1050 was a multicenter, multinational, randomized, open-label, phase 3 study to compare dacomitinib versus gefitinib (1:1 randomization) as first-line treatment for patients with advanced NSCLC with EGFR-activating mutations. All patients in the dacomitinib arm received a starting dose of $45 \mathrm{mg}$ once daily
(QD) and were permitted to reduce doses to $30 \mathrm{mg}$ QD and $15 \mathrm{mg}$ QD based on patient tolerance. All patients in the gefitinib arm received a starting dose of $250 \mathrm{mg} \mathrm{QD}$, and one dose reduction was allowed (250 $\mathrm{mg}$ every other day) based on patient's tolerance. Dacomitinib plasma trough concentrations, which were collected at pre-dose between cycle 2 and cycle 6 (28-day cycles), were used to represent dacomitinib exposure. No gefitinib plasma concentrations were collected. Because a large proportion of patients required dacomitinib dose reductions, only steady-state trough concentrations $\left(C_{\text {trough,ss }}\right)$ of dacomitinib at each dose level, defined as at least 14 days of continuous dacomitinib dosing at the same dose $(45,30$, or $15 \mathrm{mg}$ QD), were used in the analysis. Tumor imaging assessments were done at screening, at the end of cycles 1 and 2, and then every other cycle until the end-of-treatment visit. All tumor assessments used in this analysis were measured using RECIST version 1.1 and assessed by a blinded independent radiological central review. The data cutoff date was July 29, 2016, for all endpoints except OS (May 13, 2019). The institutional review board or ethics committee of each participating institution approved the trial protocol. The trial was conducted in accordance with the International Council on Harmonisation Good Clinical Practice guidelines and the provisions of the Declaration of Helsinki. All patients provided written informed consent before enrollment.

\section{Analysis Population and Grouping}

This analysis included all patients who were randomized to either the dacomitinib or gefitinib arm in the ARCHER 1050 study who received at least one dose of the study treatment. Since patients treated with dacomitinib experienced significantly longer progressionfree survival (PFS) and overall survival (OS) than those treated with gefitinib, patients randomized to different treatment arms were analyzed separately. Within each treatment arm, patients were divided into three groups based on their records of PPIs: non-PPI users (reference), PPI users, and extensive PPI users. Non-PPI users 
had no PPI use recorded prior to or during study drug (dacomitinib or gefitinib) treatment. PPI users took at least one dose of PPI during study drug treatment. Extensive PPI users took at least one dose of PPI before treatment and at least one dose of PPI during treatment, which represents the patient population with the greatest likelihood of frequent or long-term PPI use. Patients whose records showed that PPI use occurred at the end of study drug treatment or had no start date were excluded from the analysis. The duration of PPI use was calculated by [the date of last PPI dose or the date of last study drug dose (whichever was earlier) - the date of first PPI dose or the date of first study drug dose (whichever was later) +1 day]. For patients with a PPI record of "ongoing" status without an end date of last PPI dose, the end date of PPI use was imputed as the last date of study drug administration. The percentage duration of PPI use on study (\%) was calculated as $100 \times$ [the duration of PPI use/(the date of last study drug dose - the date of first study drug dose +1$)$ ].

\section{Statistical Analyses}

\section{Effect of PPI on Dacomitinib Pharmacokinetics (PK)}

A linear mixed-effects model of natural logtransformed $C_{\text {trough,ss }}$ was used to compare $C_{\text {trough,ss }}$ between reference and PPI users and between reference and extensive PPI users. The model is described as follows:

$$
\begin{aligned}
\ln \left(y_{i j k}\right)= & \mu+\left(\theta_{1} \times \mathrm{PPI}_{i}\right)+\left(\theta_{2} \times \operatorname{DOSE}_{j}\right)+\eta_{k} \\
& +\varepsilon_{i j k},
\end{aligned}
$$

where

- $y_{i j k}=$ dacomitinib $C_{\text {trough,ss }}$ for the ith PPI user group of interest, $j$ th dose level, and $k$ th patient

- $\mu=$ mean dacomitinib $C_{\text {trough,ss }}$ (natural log scale) for the reference PPI user group and dose level

- $\theta_{1}=$ PPI effect as the mean dacomitinib $C_{\text {trough,ss }}$ difference (natural log scale) between PPI user group reference $\left(\mathrm{PPI}_{i}=0\right)$ and test $\left(\mathrm{PPI}_{i}=1\right)$
- $\mathrm{PPI}_{i}=i$ th PPI group of interest [i.e. reference (non-PPI user), or test (PPI user or extensive PPI user)]

- $\theta_{2}=$ Dose level effect as the mean dacomitinib $C_{\text {trough,ss }}$ difference (natural log scale) between dose levels

- $\operatorname{DOSE}_{j}=j$ th dose level (i.e. 45,30 , or $15 \mathrm{mg}$ )

- $\eta_{k}=$ inter-patient random effect

- $\varepsilon_{i j k}=$ intra-patient random error

\section{Effect of PPI on PFS and OS of Dacomitinib and Gefitinib}

Patients were observed for survival status and subsequent cancer therapies for up to 48 months from the date of the first dose. Kaplan-Meier estimates were used to construct progression-free survival (PFS) and overall survival (OS) curves and calculate median survival with 95\% confidence intervals (CI). Univariable Cox proportional hazard regression was performed to assess whether PPI use or extensive PPI use was associated with survival $(p<0.05)$ for patients in the dacomitinib and gefitinib arms. A multivariable model incorporating patient baseline characteristics as potential confounders was conducted comparing extensive PPI users to the reference group, or if an association was found in a univariable model comparing PPI users to the reference group.

The following potential confounders were considered for the multivariable analysis: gender, age, race (Asian vs. non-Asian), baseline body weight, baseline Eastern Cooperative Oncology Group (ECOG) performance status (0 vs. 1), smoking status (former/current vs. never), EGFR mutation type (exon 19 deletion vs. L858R mutation), number of metastatic sites, number of target lesions, and number of organs with metastases. If two potential confounders were highly correlated $(|r|>0.7)$, only one was included in the multivariable analysis. For patients with potential confounder data that were missing, the median value was imputed.

The statistical analyses were conducted using the $\mathrm{R}$ functions $\operatorname{surv}()$, survfit(), ggsurvplot(), surv_median(), and $\operatorname{coxph}()$ from the survival package ( $\mathrm{R}$ version 3.6.2, $\mathrm{R}$ Foundation for Statistical Computing, Vienna, Austria). All data 
manipulation, figures, and analyses were conducted using R.

\section{RESULTS}

\section{Patient Population}

Figure 1 summarizes the number of patients treated with dacomitinib or gefitinib by PPI usage. There were 152 (67\%), 59 (26\%), and 24 (11\%) patients in the dacomitinib arm and 159 (71\%), 51 (23\%), and $19(8 \%)$ patients in the gefitinib arm grouped as non-PPI users (reference), PPI users, and extensive PPI users, respectively. Sixteen patients from the dacomitinib arm and 15 patients from the gefitinib arm were excluded from the analysis due to incomplete records of PPI use according to the prespecified PPI use definitions. The median durations of PPI use or median percent of PPI use duration on study for PPI user and extensive PPI user groups while on study were 97 days or $70 \%$ and 119 days or $100 \%$ in the dacomitinib arm, and 70 days or $48 \%$ and 253 days or $100 \%$ in the gefitinib arm, respectively (Table 1).

Baseline patient characteristics for each group are summarized in Table 1. Baseline patient characteristics were similar across all PPI groups in both the dacomitinib and gefitinib treatment arms, with the exception of race. The non-PPI users had a larger proportion of Asian patients than the PPI user and extensive PPI user groups in both the dacomitinib and gefitinib treatment arms.

\section{Pharmacokinetic Analysis}

Of the 227 patients who received dacomitinib treatment, 203 had evaluable $C_{\text {trough,ss. }}$ Of the

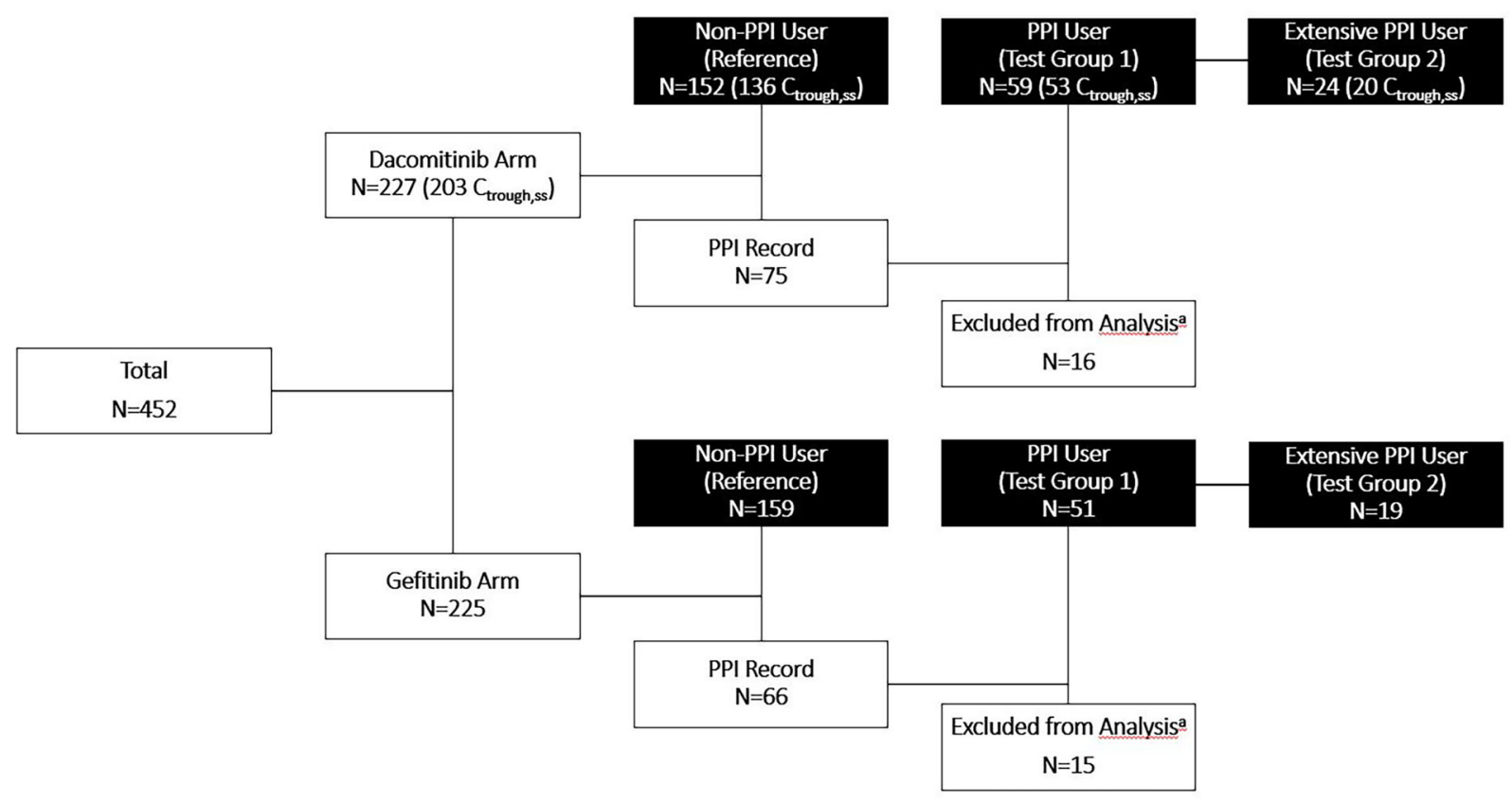

Fig. 1 Summary of patients grouped by PPI use in the intent-to-treat population randomized to dacomitinib or gefitinib treatment arms. Black boxes represent groups used in analyses. For the dacomitinib arm, the numbers of patients with evaluable $C_{\text {trough }}$ for PK analysis are included in the parentheses. PPI Record indicates any patient who had a PPI record. 'Sixteen patients in the dacomitinib arm and 15 patients in the gefitinib arm were not included in the analysis. These patients either only had a PPI record after stopping dacomitinib or gefitinib treatment, or their PPI records had no start or end date, making it impossible to determine whether those patients took PPIs concurrently with study treatment. PPI proton pump inhibitor; $C_{\text {trough,ss }}$ steady-state trough concentration 
Table 1 Baseline characteristics for patients included in the analyses

\begin{tabular}{|c|c|c|c|c|c|c|c|}
\hline \multirow[t]{2}{*}{ Variable } & \multirow[t]{2}{*}{ Category } & \multicolumn{3}{|c|}{ Dacomitinib } & \multicolumn{3}{|l|}{ Gefitinib } \\
\hline & & $\begin{array}{l}\text { Non-PPI } \\
\text { user } \\
N=152\end{array}$ & $\begin{array}{l}\text { PPI user } \\
N=59\end{array}$ & $\begin{array}{l}\text { Extensive } \\
\text { user } \\
N=24\end{array}$ & $\begin{array}{l}\text { Non-PPI } \\
\text { user } \\
N=159\end{array}$ & $\begin{array}{l}\text { PPI user } \\
N=51\end{array}$ & $\begin{array}{l}\text { Extensive } \\
\text { user } \\
N=19\end{array}$ \\
\hline $\begin{array}{l}\text { Duration of PPI use } \\
\qquad(\text { days })^{\mathrm{a}}\end{array}$ & & - & $97(1-905)$ & $119(1-745)$ & - & $70(1-904)$ & $253(3-844)$ \\
\hline \multirow[t]{3}{*}{$\begin{array}{l}\text { \% PPI use duration on } \\
\text { study }^{\text {a, b }}\end{array}$} & & - & $\begin{array}{l}70 \% \\
\quad(0.1-100 \%)\end{array}$ & $\begin{array}{l}100 \% \\
\quad(0.2-100 \%)\end{array}$ & - & $\begin{array}{l}48 \% \\
\quad(0.2-100 \%)\end{array}$ & $\begin{array}{l}100 \% \\
\quad(0.6-100 \%)\end{array}$ \\
\hline & $0-49 \%$ & - & $26(44)$ & $5(21)$ & - & $28(55)$ & $4(21)$ \\
\hline & $50-100 \%$ & & $33(56)$ & $19(79)$ & & $23(45)$ & $15(79)$ \\
\hline Age (years) ${ }^{a}$ & & $\begin{array}{l}60 \\
\quad(28-83)\end{array}$ & $66(36-87)$ & $67(37-81)$ & $\begin{array}{l}60 \\
\quad(33-83)\end{array}$ & $64(35-86)$ & $68(35-79)$ \\
\hline Weight $(\mathrm{kg})^{\mathrm{a}}$ & & $\begin{array}{l}58 \\
\quad(37-89)\end{array}$ & $63(35-130)$ & $64(35-105)$ & 59 & $63(38-94)$ & $65(43-91)$ \\
\hline $\begin{array}{l}\text { Number metastatic } \\
\text { sites }^{\mathrm{a}}\end{array}$ & & $3(1-7)$ & $3(1-8)$ & $3(1-8)$ & $3(1-9)$ & $3(1-7)$ & $4(2-6)$ \\
\hline Number target lesions ${ }^{\mathrm{a}}$ & & $2(0-4)$ & $2(0-5)$ & $2(0-5)$ & $2(0-5)$ & $1(0-4)$ & $1(0-4)$ \\
\hline $\begin{array}{l}\text { Number organ } \\
\text { metastatic sites }^{\mathrm{a}}\end{array}$ & & $2(1-6)$ & $2.5(1-5)$ & $3(1-5)$ & $2(1-5)$ & $3(1-5)$ & $3(2-4)$ \\
\hline \multirow[t]{2}{*}{ Gender $^{\mathrm{b}}$} & Male & $53(35)$ & $24(41)$ & $10(42)$ & $69(43)$ & $22(43)$ & $6(32)$ \\
\hline & Female & $99(65)$ & $35(59)$ & $14(58)$ & $90(57)$ & $29(57)$ & $13(68)$ \\
\hline \multirow[t]{2}{*}{ Race $^{b}$} & Asian & $132(87)$ & $31(53)$ & $9(38)$ & $134(84)$ & $30(59)$ & $8(42)$ \\
\hline & Non-Asian & $20(13)$ & $28(47)$ & $15(62)$ & $24(16)$ & $21(41)$ & $11(58)$ \\
\hline \multirow[t]{2}{*}{ Smoking status ${ }^{\mathrm{b}}$} & Current/former & $45(29)$ & $28(47)$ & $12(50)$ & $60(38)$ & $16(31)$ & $4(21)$ \\
\hline & Never & $107(71)$ & $31(53)$ & $12(50)$ & $99(62)$ & $35(69)$ & $15(79)$ \\
\hline \multirow[t]{2}{*}{$\mathrm{ECOG}^{\mathrm{b}}$} & 0 & $50(33)$ & $22(37)$ & $9(38)$ & $46(29)$ & $13(25)$ & $4(21)$ \\
\hline & 1 & $102(67)$ & $37(63)$ & $15(62)$ & $113(71)$ & $38(75)$ & $15(79)$ \\
\hline \multirow[t]{2}{*}{ EGFR mutation ${ }^{\mathrm{b}}$} & Exon 19 & $95(63)$ & $30(51)$ & $16(67)$ & $98(62)$ & $27(53)$ & $9(47)$ \\
\hline & $\begin{array}{l}\text { deletion } \\
\text { L858R } \\
\text { mutation }\end{array}$ & $57(37)$ & $29(49)$ & $8(33)$ & $61(38)$ & $24(47)$ & $10(53)$ \\
\hline
\end{tabular}

PPI proton pump inhibitor; ECOG PS Eastern Cooperative Oncology Group performance status; EGFR epidermal growth factor receptor

${ }^{\mathrm{a}}$ Continuous variables expressed as median (range); ${ }^{\mathrm{b}}$ Categorical variables expressed as $N(\%)$

203 patients with evaluable $C_{\text {trough,ss, }} 136$ (89\%), 53 (89\%), and 20 (83\%) patients had evaluable $C_{\text {trough,ss }}$ in the reference, PPI user, and extensive PPI user groups, respectively. Figure 2 displays the plasma concentrations of dacomitinib for each dose level by PPI user group. Dacomitinib $C_{\text {trough,ss }}$ appeared doseproportional across all three dosing levels (45, 30 , and $15 \mathrm{mg}$ ). There was no significant difference in exposure between the reference 
versus PPI users $(p=0.664)$ or the reference versus extensive PPI users $(p=0.797)$ based on the linear mixed-effects model.

\section{Effect of PPI on PFS and OS}

All potential confounders were included in the multivariable analyses except for number of target lesions, which was excluded due to high correlation with the number of organs with metastasis $(r=0.81)$ and correlation with the number of target lesions $(r=0.51)$. Median PFS and OS (95\% CI) and the potential effects of PPI use on survival [adjusted hazard ratio (HR) and $p$ value] for all patients treated with dacomitinib or gefitinib are presented in Table 2. Kaplan-Meier plots of PFS and OS are shown in Figs. 3 and 4, respectively, for patients treated with dacomitinib or gefitinib.

There was no statistically significant difference in PFS or OS between reference and PPI users $(p>0.05)$ in the dacomitinib arm. However, extensive PPI use was associated with shorter PFS, with HR of 1.94 (95\% CI 1.16-3.24, $p=0.011)$, and OS with HR of 1.77 (95\% CI $1.07-2.94, p=0.027)$, for patients treated with dacomitinib. After incorporating all specified potential confounders, extensive PPI use was not associated with shorter PFS or OS $(p>0.05)$.

There was no statistically significant difference in PFS between reference and PPI users $(p>0.05)$ or between reference and extensive PPI users $(p>0.05)$ for patients treated with gefitinib. However, both PPI users $(\mathrm{HR}=1.65$, $p=0.007)$ and extensive PPI users had shorter OS, with HR of 1.65 (95\% CI 1.15-2.36, $p=0.007)$ and HR of 1.70 (95\% CI 1.00-2.89, $p=0.050)$, respectively, when compared to reference. After incorporating all specified potential confounders, neither PPI users nor extensive PPI users were associated with shorter OS when compared to reference $(p>0.05)$.

\section{DISCUSSION}

The prevalence of ARA use was estimated to be $20-33 \%$ in patients with cancer [7, 13]. Recently, there has been heightened awareness of this subject because of potential serious consequences with certain oncology drugs. Since there are differences in the magnitude and duration of gastric $\mathrm{pH}$ elevation among various ARAs, pH-dependent DDIs can differ with the type, dose, and the dosing time of the ARA relative to that of the affected drug. Absorption of an orally administered drug with $\mathrm{pH}$-sensitive solubility may be altered, leading to undesirable clinical consequences, when it is co-administered with an ARA. In Nov 2020, FDA issued draft guidance on when and how clinical DDI studies with ARAs are needed and communicating findings in drug product labeling [13].

Of all ARAs, PPIs possess the most potent and longest duration of effect of increasing gastrointestinal (GI) $\mathrm{pH}$ [8]. PPIs are frequently prescribed to cancer patients for gastroprotection. Our analysis data set showed a high frequency of PPI use among both dacomitinib- and gefitinib-treated patients with NSCLC of EGFRactivating mutations, given that 75 out of 227 patients $(\sim 33 \%)$ in the dacomitinib arm and 66 out of 225 patients $(\sim 29 \%)$ in the gefitinib arm reported PPI use during the study. The frequency of PPI use is also heavily influenced by prescribing patterns in countries/regions. Generally, PPIs are more extensively prescribed in Western countries than in Asian countries [28-30], as demonstrated in our study, where non-Asian patients had a higher frequency of PPI use (58 and 47\% for dacomitinib and gefitinib, respectively) than Asian patients (19 and $18 \%$ for dacomitinib and gefitinib, respectively). In this analysis, the median percentage of PPI use duration on study for PPI users and extensive users was 70 and $100 \%$ in the dacomitinib arm, and 48 and $100 \%$ in the gefitinib arm, respectively. Approximately 80\% of patients in the extensive PPI user groups for both the dacomitinib and gefitinib arms were administered PPIs for more than 50\% of the entire treatment duration (Table 1). With the high frequency and long-term use of PPI in cancer patients, $\mathrm{pH}$-dependent DDIs are a potential concern. The increased $\mathrm{pH}$ from PPI use has been shown to decrease the solubility and absorption of several TKIs, which in turn leads to lower TKI exposure. These effects have been demonstrated in TKIs including dacomitinib, dasatinib, erlotinib, gefitinib, and 


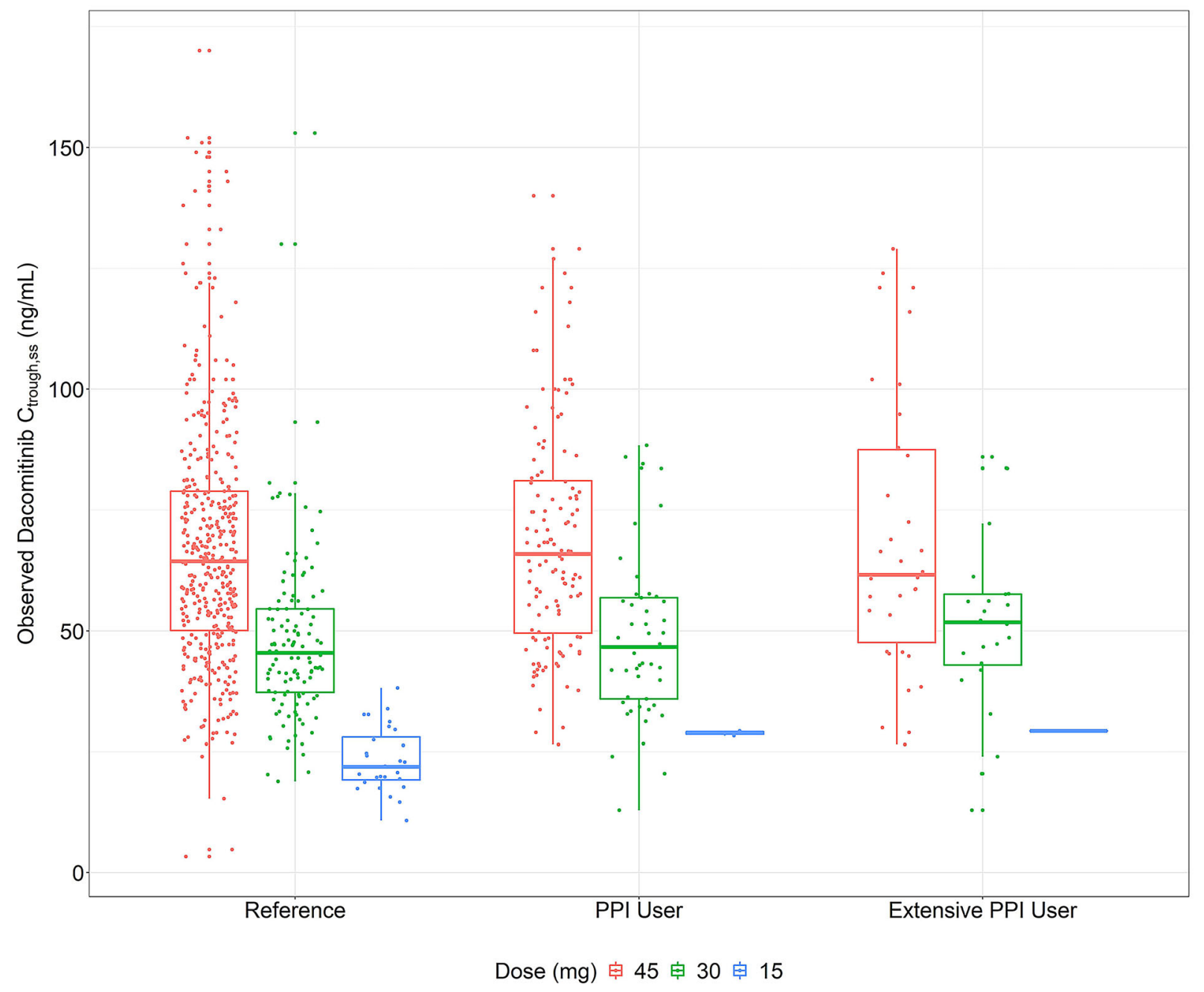

Fig. 2 Steady-state dacomitinib trough concentrations at 45, 30, and $15 \mathrm{mg}$ once daily across all PPI use groups. Red, green, and blue box and dots represent dacomitinib $\mathrm{C}_{\text {trough,ss }}$ following at least 14 consecutive days of once daily dacomitinib dosing at 45,30 , and $15 \mathrm{mg}$, respectively.

nilotinib, where decreases in AUC ranged from 26 to $65 \%$ [11, 14-22]. The decreased exposure from concomitant PPI use has led to concerns from regulatory agencies on the risk of achieving subtherapeutic plasma concentrations, thus compromising the efficacy of TKIs. As a result, these TKI US Prescribing Information (USPI) labels contraindicate or suggest avoiding the concomitant use of PPIs. These recommendations are generally based on significant decreases in drug exposure observed in dedicated PK studies with PPIs conducted in healthy
$C_{\text {trough,ss }}$ steady-state trough concentration; $n g$ nanograms; $m L$ milliliters; PPI proton pump inhibitor; $m g$ milligrams

volunteers. The dedicated clinical PK studies are generally designed to characterize a worst-case scenario for the pH-dependent DDIs by selection of PPIs and associated dosing regimens $[13,22]$. These studies generally over-predict the effect of the interaction in the real-world setting, where patients may take lower or intermittent doses of a PPI. Both dacomitinib and gefitinib are recommended to be taken in the absence of concomitant PPIs [11, 12], creating a difficult situation for patients in need of both EGFR-TKI and PPI. 
Table 2 Univariable and multivariable analyses comparing PFS and OS between PPI use groups (PPI users or extensive PPI users) for patients treated with dacomitinib or gefitinib

\begin{tabular}{|c|c|c|c|c|}
\hline PPI user group & $\begin{array}{l}\text { Non-PPI user survival } \\
\text { Months (median } 95 \% \mathrm{CI} \text { ) }\end{array}$ & $\begin{array}{l}\text { PPI user group survival } \\
\text { Months (median 95\% CI) }\end{array}$ & Adjusted HR (95\% CI) & $p$ value \\
\hline \multicolumn{5}{|l|}{ Dacomitinib } \\
\hline \multicolumn{5}{|l|}{ PFS } \\
\hline PPI users & $14.8(11.1-18.4)$ & $12.9(10.9-18.2)$ & $1.24(0.84-1.81)$ & 0.278 \\
\hline Extensive PPI users & & $11.1(7.1-18.0)$ & $1.94(1.16-3.24)$ & 0.011 \\
\hline Extensive PPI users $^{\mathrm{a}}$ & - & - & $1.35(0.69-2.65)$ & 0.375 \\
\hline \multicolumn{5}{|l|}{ OS } \\
\hline PPI users & $34.1(29.5-42.1)$ & 35.7 (26.4-NR) & $1.04(0.70-1.55)$ & 0.833 \\
\hline Extensive PPI users & & $26.3(15.6-44.4)$ & $1.77(1.07-2.94)$ & 0.027 \\
\hline Extensive PPI users $^{\mathrm{a}}$ & - & - & $1.19(0.65-2.18)$ & 0.570 \\
\hline \multicolumn{5}{|l|}{ Gefitinib } \\
\hline \multicolumn{5}{|l|}{ PFS } \\
\hline PPI users & $9.3(9.1-11.1)$ & $9.3(7.6-12.5)$ & $1.13(0.80-1.59)$ & 0.479 \\
\hline Extensive PPI users & & $10.8(7.3-12.8)$ & $1.28(0.76-2.16)$ & 0.356 \\
\hline Extensive PPI users $^{\mathrm{a}}$ & - & - & $1.08(0.61-1.94)$ & 0.787 \\
\hline \multicolumn{5}{|l|}{ OS } \\
\hline PPI users & $29.1(25.5-40.0)$ & $22.8(20.5-32.3)$ & $1.65(1.15-2.36)$ & 0.007 \\
\hline Extensive PPI users & & 26.6 (16.1-NR) & $1.70(1.00-2.89)$ & 0.050 \\
\hline PPI users ${ }^{a}$ & - & - & $1.31(0.89-1.93)$ & 0.165 \\
\hline Extensive PPI users $^{\mathrm{a}}$ & - & - & $1.01(0.56-1.82)$ & 0.981 \\
\hline
\end{tabular}

Adjusted HR and $p$ value represent the comparison between non-PPI user and PPI user group survival for each row in the table

PPI proton pump inhibitor; $H R$ hazard ratio; $C I$ confidence interval; PFS progression free survival; $O S$ overall survival; $N R$ not reached

${ }^{a}$ Multivariable analysis comparing extensive PPI users to non-PPI users includes all potential confounders listed in Table 1

While a $39 \%$ decrease in dacomitinib AUC was found in the dedicated healthy volunteer study [10], our analysis of patients from the ARCHER 1050 trial did not detect a difference in dacomitinib exposure between PPI users, extensive PPI users, and reference. The different effects of PPI use on dacomitinib exposure between the healthy volunteer study and the ARCHER 1050 study likely occurred for two reasons. First, the dedicated healthy volunteer study was designed to represent the worst case, where the maximum effect of acid suppression by PPI on dacomitinib absorption was to be achieved by administering rabeprazole, a PPI, $40 \mathrm{mg}$ daily for 7 days prior to receiving the dacomitinib dose. In comparison, patients in ARCHER 1050 self-administered PPIs for varying intervals of time and likely did not experience the maximum acid-suppressing effects of daily PPI use. Second, the populations differed 

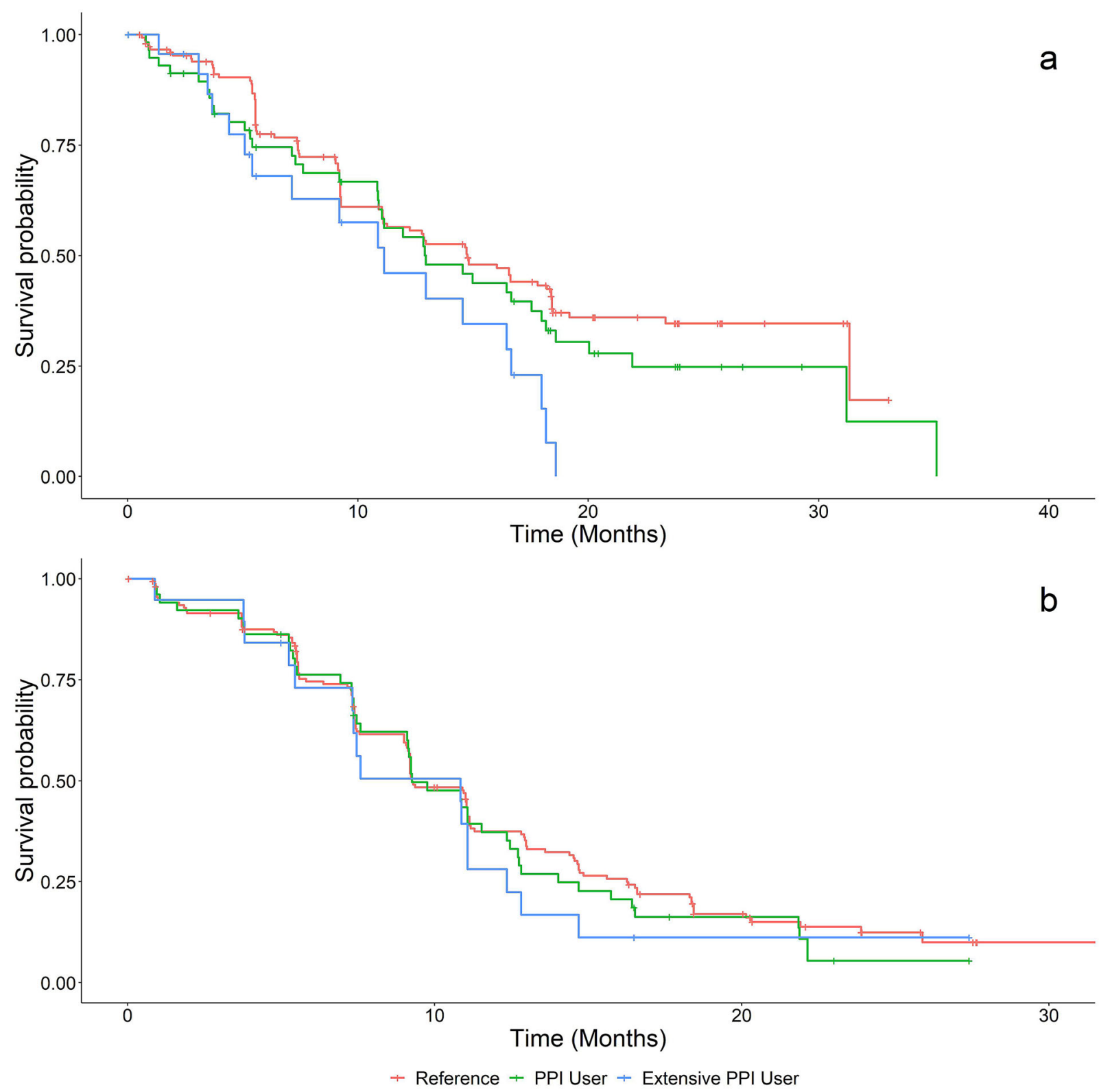

Fig. 3 Kaplan-Meier plots of PFS for patients treated with $\mathbf{a}$ dacomitinib or $\mathbf{b}$ gefitinib based on PPI use groups. Red lines represent patients in the reference (non-PPI user) group, green lines represent the PPI user group, and blue lines represent patients in the extensive PPI user

between the two studies. Participants in the ARCHER 1050 study were patients with NSCLC, reflecting a more medically complex population than healthy volunteers in the single-dosing study. The patient population had more concurrent medications and pre-existing group. PFS progression-free survival; PPI proton pump inhibitor

comorbidities, which may confound the effects of PPI on dacomitinib exposure.

Our survival analyses showed that PPI users or extensive PPI users had no statistically significant difference in PFS or OS compared with non-PPI users in patients with NSCLC treated 

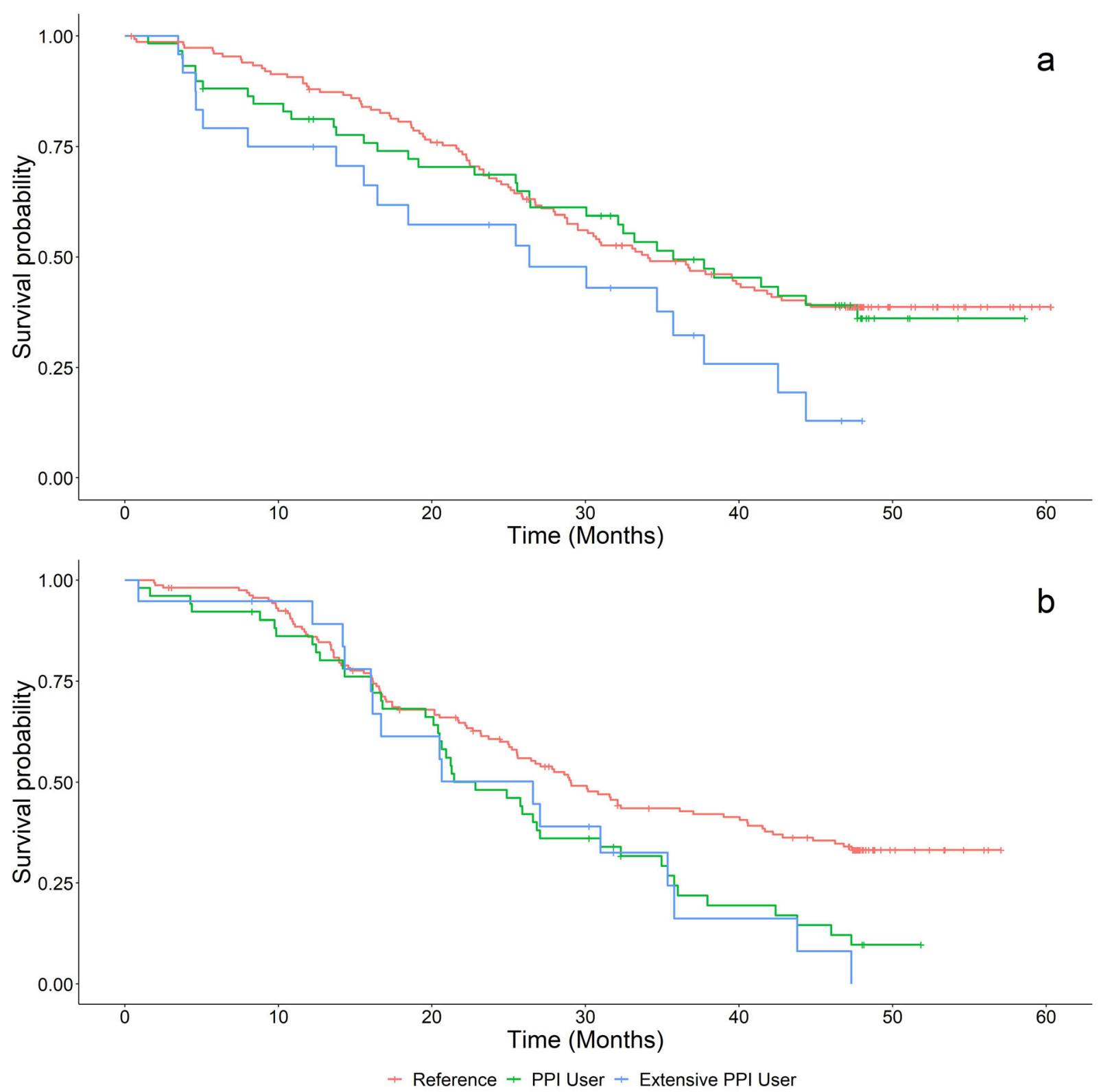

Fig. 4 Kaplan-Meier plots of OS for patients treated with $\mathbf{a}$ dacomitinib or $\mathbf{b}$ gefitinib based on PPI use groups. Red lines represent patients in the reference (non-PPI user) group, green lines represent the PPI user group, and blue

with dacomitinib or gefitinib. Similar results were reported for other TKIs with limited solubility at high $\mathrm{pH}$ [23-25]. A retrospective analysis of patients in a phase III trial for erlotinib found that the co-administration of acid-suppressive medications did not appear to impact the median plasma drug levels or survival lines represent patients in the extensive PPI user group. $O S$ overall survival; PPI proton pump inhibitor

outcomes [23]. A retrospective analysis of patients with metastatic renal cell carcinoma (RCC) found that concomitant PPI or H2RA usage was not associated with a reduction in PFS or OS for patients receiving pazopanib [24]. A pooled analysis of metastatic RCC patients treated with various vascular endothelial 
growth factor TKIs demonstrated that PPI use did not appear to negatively affect efficacy [25]. Although decreased efficacy of erlotinib with concomitant use of ARAs was controversially reported in several studies [26, 27], the increasing number of analyses suggesting an absence of PFS and OS reduction with concomitant PPI use raises the question of whether PPI contraindication is warranted if a change in exposure is found in dedicated healthy volunteer studies.

Other ARAs such as H2RAs and antacids were not included in our analysis data set. Antacids such as magnesium hydroxide, aluminum hydroxide, and calcium carbonate exert their effects by directly neutralizing gastric acid, resulting in a quick onset and a short duration of suppression of gastric acid production, with the effect usually diminishing after $2 \mathrm{~h}$ postdose [22]. H2RAs compete reversibly with histamine at the $\mathrm{H} 2$ receptors in the gastric parietal cells, leading to reduced gastric acid production, which generally lasts for up to $12 \mathrm{~h}$ at therapeutic doses [22]. Compared with PPIs, both H2RAs and antacids have less impact on the pharmacokinetics, and the interaction can be minimized by staggered dosing approaches. Coadministration of dacomitinib with multiple doses of rabeprazole (a PPI) decreased dacomitinib AUC by $39 \%$, while co-administration of dacomitinib with a local antacid $\left(\right.$ Maalox $^{\circledR}$ Maximum Strength, $400 \mathrm{mg} / 5 \mathrm{~mL}$ ) did not cause clinically relevant changes in dacomitinib concentrations [12]. Although the effect of an H2RA on the plasma concentrations of dacomitinib is unknown, it is expected to be less than that of a PPI. Thus, the effect of H2RA on survival outcomes is not expected to be significant. While the dedicated DDI study in healthy volunteers found reduced gefitinib plasma exposure when gefitinib was co-administered with ranitidine (an H2RA) and sodium bicarbonate (an antacid), the investigators of the study considered that gefitinib dose adjustment was not necessary to maintain efficacious plasma concentrations even after accounting for inter-subject variability [9]. Biologically relevant gefitinib plasma concentrations ( $>100 \mathrm{ng} / \mathrm{mL}$, equivalent to the $\mathrm{IC}_{90}$ ) were generally maintained at doses $>100 \mathrm{mg}$ QD [9].
In the ARCHER 1050 study, patients were instructed to take gefitinib $6 \mathrm{~h}$ after or $6 \mathrm{~h}$ before an H2RA, according to the gefitinib USPI label recommendations [12]. The effect of concomitant H2RA use on gefitinib exposure is therefore expected to be negligible in the gefitinib-treated patients. Moreover, concomitant gastric acid-suppressive therapy was not found to have an adverse impact on survival in a review of 130 patients with advanced EGFR mutation-positive NSCLC treated with gefitinib or erlotinib [31]. For these reasons, our analysis evaluated the effect of PPIs, a type of ARA with the highest probability of having an effect on survival, if any.

Our analysis had limitations. First, the analysis was retrospective based on the database of a randomized active control phase 3 study. Even though complete patient demographic baseline data and concomitant medication data were captured to enable multivariate analyses, post hoc analyses intrinsically carry biases, especially when there can be imbalanced distribution of baseline characteristics across non-PPI user and PPI user groups. In fact, non-PPI groups had more Asian than non-Asian patients, while PPI groups generally had more non-Asian than Asian patients, as a result of a higher frequency of PPI use in non-Asian patients than in Asian patients. Despite our approach to include baseline covariates to adjust for patient differences between PPI groups, the results of our analysis may likely be confounded by race, which has been shown to predict longer PFS and OS in patients treated with dacomitinib [5]. Second, the total number of patients in the PPI user and extensive PPI user groups was limited in our analysis data set. To overcome issues of patient selection bias and the limitation in the number of patients, future analyses including real-world data with a propensity score matching analysis should be considered. Finally, the extensive PPI user and PPI user groups were defined based on the presence of PPI records before and during the study, but there was no way to confirm compliance of PPI use during these periods. Therefore, the results of our analysis should be interpreted with caution. 


\section{CONCLUSIONS}

In conclusion, this retrospective analysis showed that the co-administration of PPIs in patients from ARCHER 1050 did not affect PFS or OS for patients receiving dacomitinib or gefitinib after accounting for potential confounders. The finding for dacomitinib was also supported by similar dacomitinib exposure observed from patients with or without the concomitant use of PPIs. As a result, the use of PPIs in patients with advanced NSCLC with activating EGFR mutations is unlikely to impact dacomitinib or gefitinib treatment efficacy despite decreased absorption of these drugs observed in PK studies with a PPI in healthy volunteers.

\section{ACKNOWLEDGMENTS}

Funding. The ARCHER 1050 study was sponsored by Pfizer and SFJ Pharmaceuticals. The journal's Rapid Service and Open Access Fees was funded by Pfizer.

Authorship. All named authors meet the International Committee of Medical Journal Editors (ICMJE) criteria for authorship for this article, take responsibility for the integrity of the work as a whole, and have given their approval for this version to be published.

Authorship Contributions. Jerry Li: analysis of data, interpretation of data, drafting the manuscript. Dana Nickens: interpretation of data. Keith Wilner: study design, acquisition of data, interpretation of data. Weiwei Tan: study design, acquisition of data, interpretation of data, drafting the manuscript.

Medical Writing, Editorial, and Other Assistance. No editorial assistance was provided.

Disclosures. All authors are employees of Pfizer Inc.
Compliance with Ethics Guidelines. The institutional review board or ethics committee of each participating institution approved the trial protocol. The trial was conducted in accordance with the International Council on Harmonisation Good Clinical Practice guidelines and the provisions of the declaration of Helsinki. All patients provided written informed consent before enrollment.

Data Availability. Upon request, and subject to review, Pfizer will provide the data that support the findings of this study. Subject to certain criteria, conditions, and exceptions, Pfizer may also provide access to the related individual anonymized participant data. See https://www.pfizer.com/science/clinical-trials/ trial-data-and-results for more information.

The authors thank the patients who participated in the ARCHER 1050 study and their families, the investigators, nurses, and site staff. The authors also thank Xin Huang, PhD and Xun Lin, PhD of Pfizer Inc. for their constructive discussions about the statistical analysis methods, and the reviewers for their comments and suggestions.

Open Access. This article is licensed under a Creative Commons Attribution-NonCommercial 4.0 International License, which permits any non-commercial use, sharing, adaptation, distribution and reproduction in any medium or format, as long as you give appropriate credit to the original author(s) and the source, provide a link to the Creative Commons licence, and indicate if changes were made. The images or other third party material in this article are included in the article's Creative Commons licence, unless indicated otherwise in a credit line to the material. If material is not included in the article's Creative Commons licence and your intended use is not permitted by statutory regulation or exceeds the permitted use, you will need to obtain permission directly from the copyright holder. To view a copy of this licence, visit http://creativecommons.org/licenses/by$\mathrm{nc} / 4.0 /$. 


\section{REFERENCES}

1. Lung Cancer. American Cancer Society. https:// www.cancer.org/cancer/lung-cancer.html. Accessed 20 Feb 2020

2. TARCEVA ${ }^{\circledR}$ (erlotinib) tablets, US Prescribing Information [Online]. Available online: https:// www.accessdata.fda.gov/drugsatfda_docs/label/ 2010/021743s14s16lbl.pdf. Accessed 21 Feb 2020

3. Sullivan I, Planchard D. Next-generation EGFR tyrosine kinase inhibitors for treating EGFR-mutant lung cancer beyond first line. Front Med (Lausanne). 2016;3:76. https://doi.org/10.3389/fmed. 2016.00076 .

4. Mok TS, Cheng Y, Zhou X, Lee KH, Nakagawa K, Niho S, Chawla A, Rosell R, Corral J, Migliorino MR, Pluzanski A, Noonan K, Tang Y, Pastel M, Wilner $\mathrm{KD}, \mathrm{Wu}$ YL. Updated overall survival in a randomized study comparing dacomitinib with gefitinib as first-line treatment in patients with advanced nonsmall-cell lung cancer and EGFR-activating mutations. Drugs. 2020. https://doi.org/10.1007/s40265020-01441-6.

5. Wu YL, Cheng Y, Zhou X, Lee KH, Nakagawa K, Niho S, Tsuji F, Linke R, Rosell R, Corral J, Migliorino MR, Pluzanski A, Sbar EI, Wang T, White JL, Nadanaciva S, Sandin R, Mok TS. Dacomitinib versus gefitinib as first-line treatment for patients with EGFR-mutation-positive non-small-cell lung cancer (ARCHER 1050): a randomised, open-label, phase 3 trial. Lancet Oncol. 2017;18(11):1454-66. https://doi.org/10.1016/S1470-2045(17)30608-3.

6. Budha NR, Benet LZ, Ware JA. Response to "Drug interactions produced by proton pump inhibitors: not simply a pH effect." Clin Pharmacol Ther. 2013;93(2):151. https://doi.org/10.1038/clpt.2012. 206.

7. Smelick GS, Heffron TP, Chu L, Dean B, West DA, Duvall SL, Lum BL, Budha N, Holden SN, Benet LZ, Frymoyer A, Dresser MJ, Ware JA. Prevalence of acid-reducing agents (ARA) in cancer populations and ARA drug-drug interaction potential for molecular targeted agents in clinical development. Mol Pharm. 2013;10(11):4055-62. https://doi.org/ $10.1021 / \mathrm{mp} 400403 \mathrm{~s}$.

8. Numico G, Fusco V, Franco P, Roila F. Proton Pump Inhibitors in cancer patients: how useful they are? A review of the most common indications for their use. Crit Rev Oncol Hematol. 2017;111:144-51. https://doi.org/10.1016/j.critrevonc.2017.01.014.

9. Tang W, Tomkinson H, Masson E. Effect of sustained elevated gastric $\mathrm{pH}$ levels on gefitinib exposure. Clin Pharmacol Drug Dev. 2017;6(5): 517-23. https://doi.org/10.1002/cpdd.337.

10. Ruiz-Garcia A, Masters JC, Mendes da Costa L, LaBadie RR, Liang Y, Ni G, Ellery CA, Boutros T, Goldberg Z, Bello CL. Effect of food or proton pump inhibitor treatment on the bioavailability of dacomitinib in healthy volunteers. J Clin Pharmacol. 2016;56(2):223-30. https://doi.org/10.1002/ jcph.588.

11. IRESSA ${ }^{\circledR}$ (gefitinib) tablets: US Prescribing Information [Online]. Available online: https://www. accessdata.fda.gov/drugsatfda_docs/label/2018/ 206995s003lbl.pdf. Accessed 21 Feb 2020

12. VIZIMPRO ${ }^{\circledR}$ (dacomitinib) tablet: US Prescribing Information [Online]. Available online: https:// www.accessdata.fda.gov/drugsatfda_docs/label/ 2018/211288s000lbl.pdf. Accessed 21 Feb 2020

13. US Food \& Drug Administration. (November 2020). Evaluation of Gastric pH-Dependent Drug Interactions With Acid-Reducing Agents: Study Design, Data Analysis, and Clinical Implications. https:// www.fda.gov/media/144026/download. Accessed 29 Mar 2021

14. Grunwald VH, Hidalgo M. Development of the epidermal growth factor receptor inhibitor Tarceva (OSI-774). Adv Exp Med Biol. 2003;532:235-46. https://doi.org/10.1007/978-1-4615-0081-0_19.

15. Shepherd FA, Pereira JR, Ciuleanu T, Tan EH, Hirsh V, Thongprasert S, Campos D, Maoleekoonpiroj S, Smylie M, Martins R, et al. Erlotinib in previously treated non-small-cell lung cancer. N Engl J Med. 2005;353(2):123-32. https://doi.org/10.1056/ NEJMoa050753.

16. TASIGNA® (nilotinib) capsules: US Prescribing Information [Online]. Available online: https:// www.accessdata.fda.gov/drugsatfda_docs/label/ 2019/022068s031lbl.pdf. Accessed 21 Feb 2020

17. Abbas R, Leister C, Sonnichsen D. A clinical study to examine the potential effect of lansoprazole on the pharmacokinetics of bosutinib when administered concomitantly to healthy subjects. Clin Drug Investig. 2013;33(8):589-95. https://doi.org/10. 1007/s40261-013-0103-z.

18. Koch KM, Im YH, Kim SB, Ribate AU, Stephenson J, Botbyl J, Cartee L, Holshouser J, Ridgway D. Effects of esomeprazole on the pharmacokinetics of lapatinib in breast cancer patients. Clin Pharmacol Drug Dev. 2013;2(4):336-41. https://doi.org/10.1002/ cpdd. 45 .

19. Keyvanjah K, DiPrimeo D, Li A, Obaidi M, Swearingen D, Wong A. Pharmacokinetics of neratinib during coadministration with lansoprazole in 
healthy subjects. Br J Clin Pharmacol. 2017;83(3): 554-61. https://doi.org/10.1111/bcp.13132.

20. Yin OQP, Gallagher N, Fischer D, Demirhan E, Zhou W, Golor G, Schran H. Effect of the proton pump inhibitor esomeprazole on the oral absorption and pharmacokinetics of nilotinib. J Clin Pharmacol. 2010;50(8):960-7. 0091270009346061.

21. Tan AR, Darlene G, Stein MN, Lindquist D, Edenfield JW, Martin JC, Gregory C, Suttle AB, Tada H, Botbyl J, Stephenson JJ. Effects of ketoconazole and esomeprazole on the pharmacokinetics of pazopanib in patients with solid tumors. Cancer Chemother Pharmacol. 2013;71(6):1635-43. https:// doi.org/10.1007/s00280-013-2164-3.

22. Zhang L, Wu F, Lee SC, Zhao H, Zhang L. pH-dependent drug-drug interactions for weak base drugs: potential implications for new drug development. Clin Pharmacol Ther. 2014;96(2):266-77. https://doi.org/10.1038/clpt.2014.87.

23. Hilton JF, Tu D, Seymour L, Shepherd FA, Bradbury PA. An evaluation of the possible interaction of gastric acid suppressing medication and the EGFR tyrosine kinase inhibitor erlotinib. Lung Cancer. 2013;82(1):136-42. https://doi.org/10.1016/j. lungcan.2013.06.008.

24. McAlister RK, Aston J, Pollack M, Du L, Koyama T, Chism DD. Effect of concomitant pH-elevating medications with pazopanib on progression-free survival and overall survival in patients with metastatic renal cell carcinoma. Oncologist. 2018;23(6):686-92. https://doi.org/10.1634/ theoncologist.2017-0578.

25. Lalani AA, McKay RR, Lin X, Simantov R, Kaymakcalan MD, Choueiri TK. Proton pump inhibitors and survival outcomes in patients with metastatic renal cell carcinoma. Clin Genitourin Cancer.
2017;15(6):724-32. https://doi.org/10.1016/j.clgc. 2017.05.019.

26. Uchiyama AAT, Silva P, Lopes MSM, Yen CT, Ricardo ED, Mutao T, Pimenta JR, Machado LM, Shimba DS, Peixoto RD. Proton pump inhibitors and oncologic treatment efficacy: a practical review of the literature for oncologists. Curr Oncol. 2021;28(1):783-99. https://doi.org/10.3390/ curroncol28010076.

27. Sharma N, Chau WY, Dobruskin L. Effect of longterm proton pump inhibitor therapy on hemoglobin and serum iron levels after sleeve gastrectomy. Surg Obes Relat Dis. 2019;15(10):1682-9. https:// doi.org/10.1016/j.soard.2019.06.019.

28. Luo H, Fan Q, Xiao S, Chen K. Changes in proton pump inhibitor prescribing trend over the past decade and pharmacists' effect on prescribing practice at a tertiary hospital. BMC Health Serv Res. 2018;18(1):537. https://doi.org/10.1186/s12913018-3358-5.

29. Zeng W, Finlayson AE, Shankar S, de Bruyn W, Godman B. Prescribing efficiency of proton pump inhibitors in China: influence and future directions. BMC Health Serv Res. 2015;15:11. https:// doi.org/10.1186/s12913-014-0638-6.

30. Yu SY, Lee B, McGuire TM, Lee HJ, Hollingworth SA. Consumption of medicines used for gastric acidrelated disorders in Australia and South Korea: a cross-country comparison. Eur J Clin Pharmacol. 2020;76(4):547-55. https://doi.org/10.1007/ s00228-019-02798-8.

31. Zenke Y, Yoh K, Matsumoto S, Umemura S, Niho S, Ohmatsu H, Goto K, Ohe Y. Clinical impact of gastric acid-suppressing medication use on the efficacy of erlotinib and gefitinib in patients with advanced non-small-cell lung cancer harboring EGFR mutations. Clin Lung Cancer. 2016;17(5): 412-8. https://doi.org/10.1016/j.cllc.2016.01.006. 